\title{
ASSESSMENT OF NATURAL RADIOACTIVITY IN SELECTED GRASS SAMPLES COLLECTED FROM NORTHERN REGIONS OF OMAN
}

\author{
A. AL-HARMALI \\ Physics Department, Science College, Sultan Qaboos University, Oman
}

\begin{abstract}
In normal conditions, the total levels of radioactivity are not greatly influenced by radioactivity from nuclear power accidents, industrial plants or research facilities. In this study, the variation of radionuclides concentrations in grass was measured, and the levels of ${ }^{238} U,{ }^{232} \mathrm{Th},{ }^{235} \mathrm{U}$ and ${ }^{40} \mathrm{~K}$ were established at $0.91-5.29,<D L-1.97,<D L-280$, and $<D L$ - 1.2 (all in Bq. $\mathrm{kg}^{-1}$ ), respectively. The dose rate (D) was recorded ranging between 2.1-14 nGy/h, whereas the annual effective dose $\left(H_{R}\right)$ was found to be in the range of $(0.3-17) * 10^{-2} \mathrm{mSv} / y r$, with four values exceeding the globally admissible value $7 * 10^{-2} \mathrm{mSv} / y r$. Thus, the annual effective dose from grass in those areas must be monitored for residents' protection. Equivalent radium activity $\left(\mathrm{Ra}_{\text {eq }}\right)$ found in the range of $6.0-25 \mathrm{~Bq} \mathrm{~kg}^{-1}$ and the three hazard parameters $H_{i n}, H_{e x}$ and $I_{\gamma r}$ were all found less than (1), the global safe limit. The results ensure there is no significance hazards of radiation from plants in the studied area.
\end{abstract}

KEYWORDS: Radioactivity, Grass, HPGe Detector \& Gamma Rays

Received: Sep 07, 2019; Accepted: Oct 27, 2019; Published: Jul 23, 2020; Paper Id.: IJCSEIERDAUG20202

\section{INTRODUCTION}

Higher concentrations of radionuclides can be hazardous to humans and cause them chronic lung diseases; lung, pancreas or kidney cancers; leukemia; and necrosis of the mouth [1]. Most wadis (valleys) in Oman have headwaters that descend from the mountains towards the deserts or coast. Most of the wadis that have been studies come down from the Hajar mountains either towards the east (coastal area) or the west (desert). Since there is underground water along these valleys, settlements and agriculture are common in the area. The research conducted for this study generated data about the levels of radiactivity in fifteen locations in north area of Oman.

\subsection{Gamma-Ray Spectroscopy}

The three most common detectors of radioactivity in gamma spectroscopy areThallium activated Sodium Iodide (NaI), Lanthanum Bromide (LaBr) and High Purity Germanium (HPGe). Each detector offers a different degree of resolution, or sharpness, of peaks in the spectrum. Resolution will be better vertical lines peaks and weak thickness, among the above mentioned detectors, and this is what makes HPGe detectors the best of the three. Figure 1 compares the resolution of the different detectors of the radionuclide ${ }^{239} \mathrm{Pu}$. The HPGe detector shows sharp and thin energy lines [2]. 


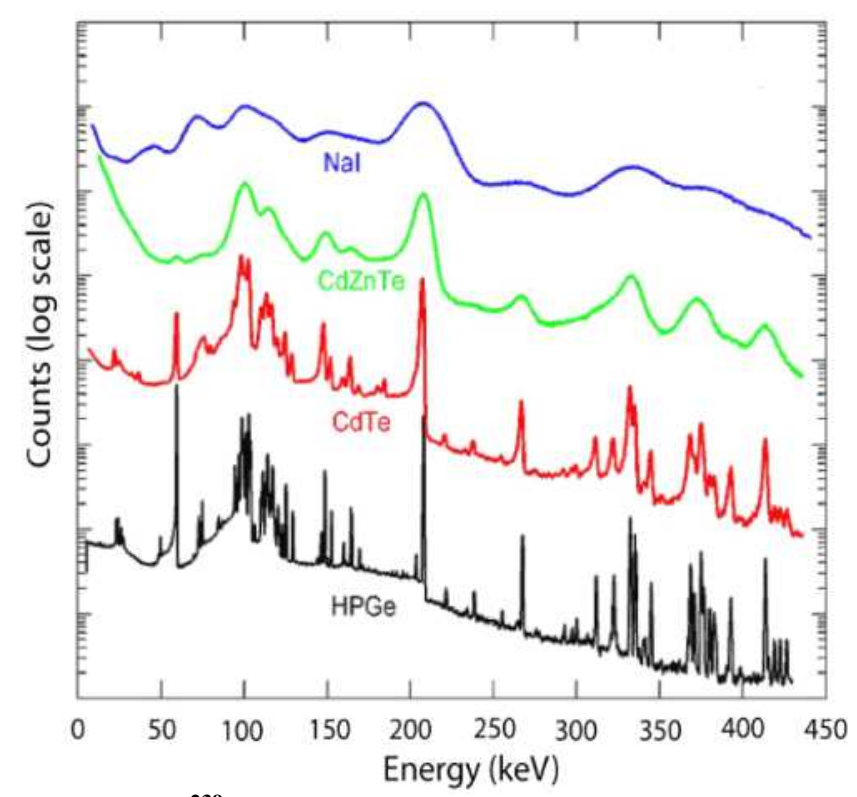

Figure 1: Spectra of ${ }^{239} \mathrm{Pu}$ radionuclide determined by different detectors

\section{MATERIALS AND METHODS}

\subsection{Grass Samples, Collection and Preparation}

Radioactivity levels had not been measured in northern Oman, despite the region's importance for agriculture and the various industries. To redress that, this study was designed. The most accessible wadis were identified, and samples were collected from headwaters and estuaries that were approximately ten kilometers apart. There were 15 locations in total, as shown on the map in figure 2.

Also, the study took into account available data about rainfall in the area between December and April within a 27-year period (1977-2003). The same source revealed that the annual percentage in Oman taken as a whole ranged between $57.8 \%-82.9 \%$. It must be added that $50 \mathrm{~mm}$ of rain in a day is a rare phenomenon in Oman (the figures are between 0.4 to $2.9 \%$ ) [3]. In spite of that, when it rains, the wadis are flooded, and soil erosion takes place. As a result, radioactivity is distributed along the wadis tracks in varying ways.

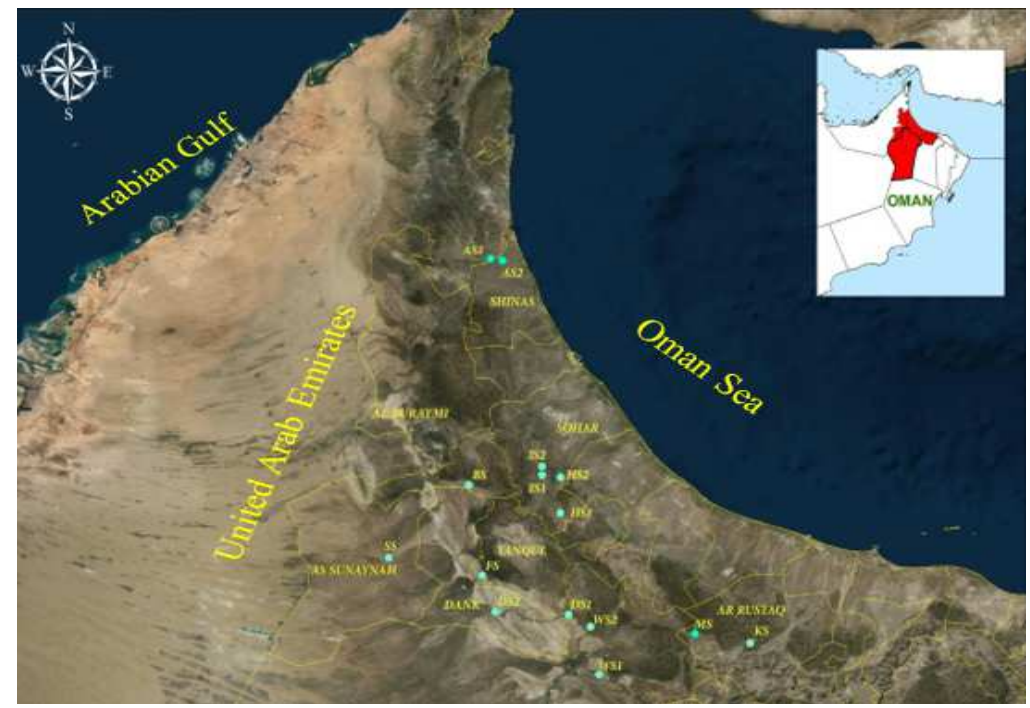

Figure 2: Map represents locations of grass samples 
The 15 green grass samples were taken with a sharp knife, kept in plastic bags, and appended with the corresponding GPS coordinates (Table 1). Scientific names were given to the grass samples based on sources [4] published by the Omani Botanic Garden. The grass samples were dried and then grinded. They were subsequently placed in containers, each weighing $58 \mathrm{~g}$. The samples were later on sealed for at least 4 weeks to establish the balance between the ${ }^{226} \mathrm{Ra}$ and its short lived progeny [5]

Table 1: Grass samples codes and locations

\begin{tabular}{|c|c|c|c|}
\hline $\begin{array}{l}\text { Sample } \\
\text { Code }\end{array}$ & $\begin{array}{c}\text { Location } \\
\text { (W.=WADI) }\end{array}$ & $\begin{array}{c}\text { Latitude N } \\
\text { (Deg.Min.S) }\end{array}$ & $\begin{array}{l}\text { Longitude E } \\
\text { (Deg.Min.S) }\end{array}$ \\
\hline G1 & W. ASWAD & $24 \square 52$ '43.2" & $56 \square 17$ '02.9" \\
\hline G2 & W. ASWAD & $24 \square 52$ '17.1" & $56 \square 19^{\prime} 46.8$ " \\
\hline G3 & W. HIBI & $23 \square 54$ '53.6" & $56 \square 3323.3 "$ \\
\hline G4 & W. HIBI & $24 \square 02$ '57.9" & $56 \square 3326 "$ \\
\hline G5 & W. HILTI & $24 \square 0329 "$ & $56 \square 29$ '06.9" \\
\hline G6 & W.HILTI & $24 \square 0526.8 "$ & $56 \square 29$ '04.3" \\
\hline G7 & BURAIMI & $24 \square 01$ '17" & $56 \square 11 ' 54.8$ " \\
\hline G8 & W. ALFATH & $23 \square 40 ' 46.6^{\prime \prime}$ & $56 \square 15$ '03.1" \\
\hline G9 & W. ALSAIFA & $23 \square 44 ' 44.6^{\prime \prime}$ & $55 \square 53$ '06.9" \\
\hline G10 & W. DHUNK & $23 \square 3148.3 "$ & $56 \square 35^{\prime} 16^{\prime \prime}$ \\
\hline G11 & W. DHUNK & $23 \square 3228.9^{\prime \prime}$ & $56 \square 18 \mathrm{\prime} 06^{\prime \prime}$ \\
\hline G12 & Wadi WAHRA & $23 \square 18^{\prime} 11.0^{\prime \prime}$ & $56 \square 4229 "$ \\
\hline G13 & WadiWahra & $23 \square 27 ' 27.1^{\prime \prime}$ & $56 \square 4026.9 "$ \\
\hline G14 & Mahbab & $23 \square 2729.0^{\prime \prime}$ & $57 \square 04$ '58.6" \\
\hline G15 & KHADA & $23 \square 2521 "$ & $57 \square 17$ '55.9" \\
\hline
\end{tabular}

\subsection{Spectrum Analysis}

Using the photo-peak of ${ }^{234} \mathrm{Th}$ radionuclide, the activity concentration of ${ }^{238} \mathrm{U}$ was estimated, while the activity concentration of ${ }^{232} \mathrm{Th}$ was calculated by the gamma ray given by ${ }^{228} \mathrm{Ac}$. The activity concentrations of ${ }^{137} \mathrm{Cs},{ }^{40} \mathrm{~K}$ and ${ }^{235} \mathrm{U}$ and daughters from their series were measured by using their gamma ray photo-peaks. The activity concentration analysis was carried out using Genie analysis software and the spectrum was converted to pdf format in order to get Nuclide Identification Reports for each sample like the one demonstrated in figure 3.

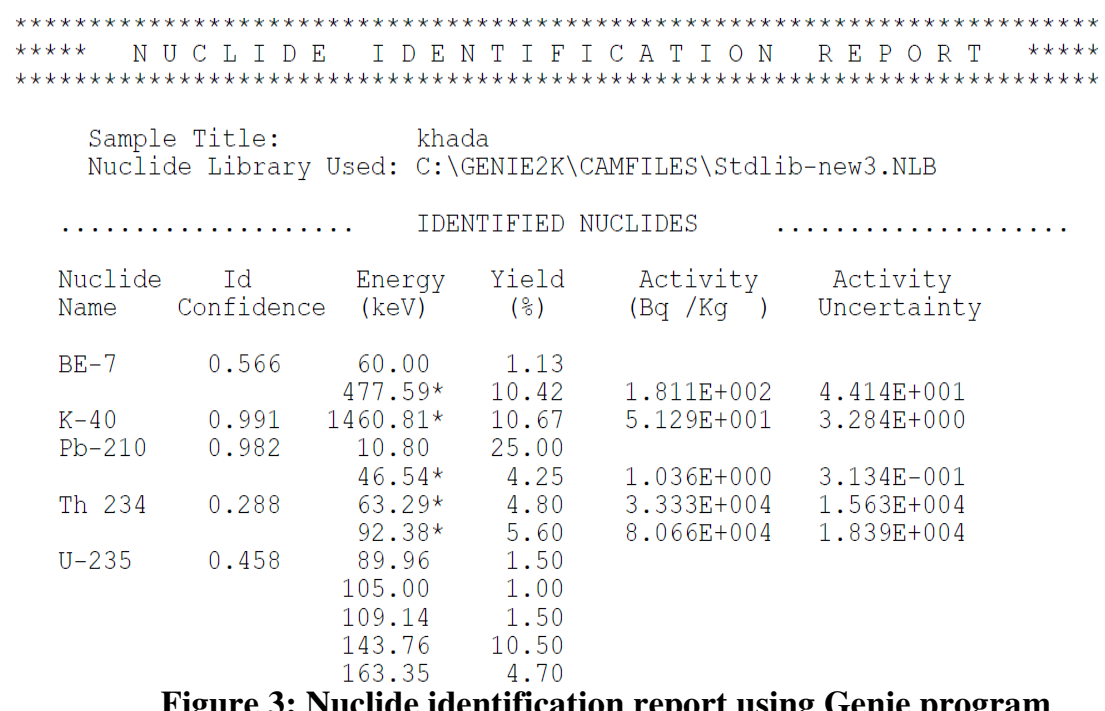

Figure 3: Nuclide identification report using Genie program 


\subsection{Minimum Detectable Activity (MDA)}

Environmental gamma spectrometrists aim particularly to minimize the minimum detectable activity (MDA) which refers to the smallest $\mathrm{c}$ value of radioactivity concentration of a radionuclide that can be detected above the background signal. The significant factors which can impact the MDA value include the particular radionuclide of interest, the detector resolution, calibration geometry, etc. [6].

\section{RESULTS AND DISCUSSIONS}

\subsection{Activity Concentrations in Grass}

The concentrations of the main radionuclides ${ }^{238} \mathrm{U},{ }^{232} \mathrm{Th},{ }^{40} \mathrm{~K}$ and ${ }^{235} \mathrm{U}$ for the 15 grass samples are represented in figure (4).

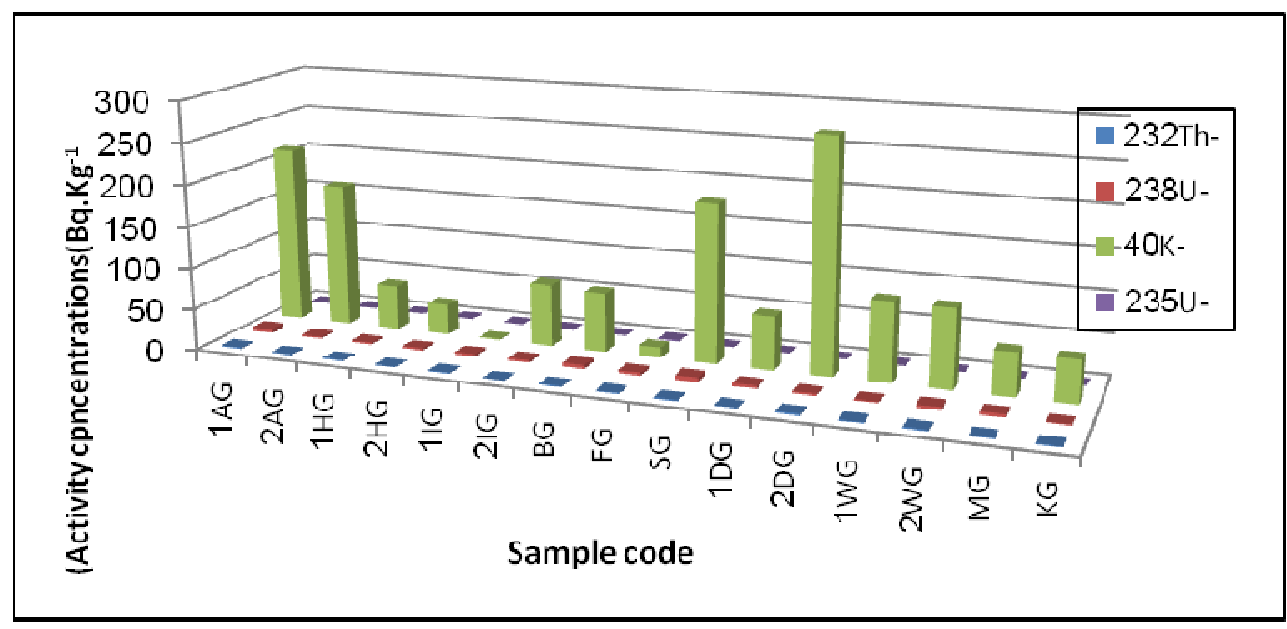

Figure 4: Activity concentrations of main radionuclides in the samples of grass

The maximum activity concentration of ${ }^{238} \mathrm{U}$ was $5.3 \pm 0.8 \mathrm{~Bq} \cdot \mathrm{kg}^{-1}$, as reported in the SG sample, whereas the lowest activity concentration was $0.9 \pm 0.4 \mathrm{~Bq} \cdot \mathrm{kg}^{-1}$, as found in the $\mathrm{KG}$ sample. The highest concentration of ${ }^{232} \mathrm{Th}$ was registered in DG2 with $2.0 \pm 0.5 \mathrm{~Bq} \cdot \mathrm{kg}^{-1}$, while in eleven other locations, it was lower than the detection limits. The said detection limits were calculated and are shown in the figure above. ${ }^{40} \mathrm{~K}$ was found at maximum levels in AG1 with a value of $215 \pm 8 \mathrm{~Bq} \cdot \mathrm{kg}^{-1}$, whereas in IG1, it was below the detection limit. The concentrations of ${ }^{235} \mathrm{U}$ were below the detection limits in five sites; the highest level was detected in FG at $1.2 \pm 0.4 \mathrm{~Bq} \cdot \mathrm{kg}^{-1} .{ }^{40} \mathrm{~K}$ showed the highest levels of all the radionuclides. The results of the grass samples represented that the activity concentrations of $U$ were higher than Thin all the samples.

Table 2: Activity concentrations of main radionuclides in soil and grass from different studies

\begin{tabular}{|c|l|c|}
\hline \multirow{3}{*}{ Radionuclide } & \multicolumn{1}{|c|}{ Country } & Activity concentrations (Bq.kg ${ }^{-1}$ ) \\
\hline \multirow{5}{*}{${ }^{232} \mathrm{Th}$} & Present study & $1.97-<\mathrm{DL}$ \\
\cline { 2 - 3 } & Kuwait [7] & - \\
\cline { 2 - 3 } & Sweden [8] & 20 \\
\cline { 2 - 3 } & Sweden [9] & - \\
\cline { 2 - 3 } & Bangladesh [10] & 3.66 \\
\cline { 2 - 3 } & China[11] & - \\
\hline \multirow{3}{*}{} & Present study & $5.29-0.91$ \\
\cline { 2 - 3 } & Kuwait & - \\
\hline
\end{tabular}




\begin{tabular}{|c|l|c|}
\hline${ }^{238} U$ & Sweden & 430 \\
\cline { 2 - 3 } & Sweden & - \\
\cline { 2 - 3 } & Bangladesh & 1.26 \\
\hline \multirow{5}{*}{40} & China & - \\
\hline \multirow{5}{*}{$\mathrm{K}$} & Present study & $279.7-<$ DL \\
\cline { 2 - 3 } & Kuwait & - \\
\cline { 2 - 3 } & Sweden & - \\
\cline { 2 - 3 } & Sweden & 134.95 \\
\cline { 2 - 3 } & Bangladesh & - \\
\cline { 2 - 3 } & China & \\
\hline
\end{tabular}

\section{ASSESSMENT OF HAZARDS}

Exposure to radiation can be established in terms of certain parameters, such as the absorbed dose rate,Gamma representative level, radium equivalent activity, annual effective dose and internal and external hazard indices as presented in Table 4.

Table 4: Hazard parameters of grass samples collected from different studies.

\begin{tabular}{|c|c|c|c|c|c|c|}
\hline $\begin{array}{c}\text { Sample } \\
\text { Code }\end{array}$ & $\begin{array}{c}\text { D } \\
\left(\mathrm{nGy}^{\mathrm{1}}\right)\end{array}$ & $\begin{array}{c}\mathrm{H}_{\mathrm{R}}\left(\begin{array}{l}* 10^{-} \\
2\end{array}\right) \\
\left(\mathrm{mSv}^{-} \mathrm{yr}^{-}\right. \\
\left.\mathbf{1}^{-}\right)\end{array}$ & $\begin{array}{c}\mathbf{R}_{\text {aeq }} \\
\left(\mathrm{Bq}^{-k^{-1}}\right)\end{array}$ & $\mathbf{H}_{\text {in }}$ & $\mathbf{H}_{\mathrm{ex}}$ & $\mathbf{I} \gamma \mathbf{r}$ \\
\hline G1 & 12 & 14 & 24.9 & 0.08 & 0.06 & 0.18 \\
\hline G2 & 8.7 & 12 & 19.8 & 0.07 & 0.04 & 0.14 \\
\hline G3 & 3.9 & 0.5 & 12.3 & 0.05 & 0.02 & 0.06 \\
\hline G4 & 2.9 & 0.4 & 6.26 & 0.02 & 0.02 & 0.05 \\
\hline G5 & 2.1 & 0.3 & 9.76 & 0.05 & 0.01 & 0.03 \\
\hline G6 & 4.5 & 0.6 & 9.99 & 0.04 & 0.02 & 0.07 \\
\hline G7 & 5.7 & 0.7 & 11.0 & 0.04 & 0.03 & 0.09 \\
\hline G8 & 2.8 & 0.3 & 9.40 & 0.04 & 0.02 & 0.04 \\
\hline G9 & 11 & 14 & 23.2 & 0.08 & 0.06 & 0.18 \\
\hline G10 & 4.7 & 0.6 & 6.00 & 0.02 & 0.03 & 0.07 \\
\hline G11 & 14 & 17 & 27.8 & 0.08 & 0.07 & 0.22 \\
\hline G12 & 5.5 & 0.6 & 15.7 & 0.06 & 0.03 & 0.09 \\
\hline G13 & 6.5 & 0.8 & 17.8 & 0.07 & 0.04 & 0.10 \\
\hline G14 & 4.6 & 0.6 & 11.9 & 0.05 & 0.03 & 0.07 \\
\hline G15 & 3.2 & 0.4 & 10.5 & 0.04 & 0.02 & 0.05 \\
\hline $\begin{array}{c}\text { World } \\
\text { Average }\end{array}$ & 57 & 7.0 & 128.7 & $<1$ & $<1$ & $<1$ \\
\hline
\end{tabular}

The maximum values of the, annual effective dose, dose rate, equivalent radium activity, internal hazard index, external hazard index and gamma representative level index were all recorded in G11 sample as: $17 * 10^{-2} \mathrm{mSv}_{\mathrm{yr}}^{-}$ ${ }^{1}, 14 \mathrm{nGy} \cdot \mathrm{h}^{-1}, 27.8 \mathrm{~Bq} \cdot \mathrm{kg}^{-1}, 8 * 10^{-2}, 7 * 10^{-2}$ and 0.22 , respectively. To interpret this result, Wadi Dunk (Feda) was one of the famous permanent runoff wadis in Oman. The wadi is characterized by very severe sloping mountains. Wadis flowing from all the wadis in Yanqul disgorge their bounty into this Wadi Dunk. As noticed from table 4, the annual effective doses were registered to be higher than the world-wide average value in four locations G1, G2, SG and G11. Other values were below the worldwide admissible values. The lowest dose rate and annual effective dose were registered in G5 at $2.1 \mathrm{nGy} . \mathrm{h}^{-}$ ${ }^{1}$ and $3.0 * 10^{-3} \mathrm{mSv}_{\mathrm{yr}}{ }^{-1}$, respectively. The same value of was recorded in G8 for the annual effective dose. The smallest value of equivalent radium activity was found in $\mathrm{G} 10$ at $6.0 \mathrm{~Bq} \cdot \mathrm{kg}^{-1}$. Lower values of external and gamma representative level indices were found both in G5 at 0.01 and 0.03 , respectively; whereas the lowest internal hazard index was found in 
G2 at 0.02. In general, the values of all the parameters were lower and far from the standard limits recommended by UNESCAR [12].

\section{CONCLUSIONS}

This study investigated the radioactivity levels in the grass samples from 15 locations in northern Oman. It recorded the activity concentrations of radionuclide parents and their daughters'. Most of values measured were lower than the MDA and the worldwide average values. The G11 sample registered the maximum values of the hazard indices,internal hazard index,external hazard index, dose rate, annual effective dose, equivalent radium activity, and gamma representative level index. Still, these values were lower than the global admissible values. In conclusion, the measurement of radioactivity in grass samples from these 15 areas of northern Oman showed radioactivity concentrations far below the international limits and can, therefore, be considered safe for human habitation.

\section{REFERENCES}

1. Bielajew, A. F. Fundamentals of Radiation Dosimetry and Radiological Physics. The University of Michigan.U. S. A. Ann Arbor, Michigan 48109-2104 (2005).

2. Elmenshaz, F. M. Measurements of Norm in Environmental Samples. Master's thesis, University of Surrey.. (2009)

3. Kwarteng, A. Y., Dorvlo, S., \&Vijaya, G. T. Analysis of a 27-year rainfall data ( 1977 - 2003 ) in the Sultanate of Oman, International journal of climatalogy, (29) 605-617. (2009).

4. Pickering, H., \&Patzelt, A. Field guide to the wild plants of Oman. Royal Botanic Gardens, Kew Publishing. ISBN 978-1-84246177(2008).

5. Al-Leswas. Salim, P. Evaluation of Natural Radioactivity in Environmental Samples., University of Surrey, Master thesis. (2010).

6. Leroy, C., \&Rancoita, P. G. Principles of radiation interaction in matter and detection. London, UK: World Scientific journal (Vol. 2). (2004).

7. Saad, R., \& Farhan, A. R. Comparative Study of Desert Truffles from Kuwait and Other Countries in the Middle East for Radionuclide Concentration, Humana Press Inc, 309-315. (1999).

8. Pallavicini, N. Activity concentration and transfer factors of natural and artificial radionuclides in the Swedish counties of Uppsala and Jämtland. Master's Thesis in Environmental Science,

9. Examensarbeten 2011:22, Swedish University of Agricultural Sciences. (2011).

10. -Yosief Tesfatsion. Assessments in the pasture lands located in the counties of Uppsala and Jämtland, Swedish University of Agricultural Sciences. Master's Thesis in Environmental Science(2012).

11. Chakraborty, S. R., Azim, R., \& Rahman, A. K. M. R. Radioactivity Concentrations in Soil and Transfer Factors of Radionuclides from Soil to Grass and Plants in the Chittagong City of Bangladesh, Journal of Physical Science 24(1), 95113(2013).

12. Dai, L., H. Wei, and L. Wang. Spatial distribution and risk assessment of radionuclides in soils around a coal-fired power plant: A case study from the city of Baoji, China. Environmental Research journal. 104:201-208..(2007).

13. United Nations Scientific Committee on the Effects of Atomic Radiation UNSCEAR, B. Sources and Effects Of Ionizing Radiation. New York, USA. (2000). 